JUDICIAL DECISIONS

\title{
Judicial Decisions Regarding Expert Evidence on Violence Risk Assessment
}

\author{
Alana N. Cook \\ Cook Psychological Services \& Simon Fraser University \\ Eva Dvorakova \\ Hertfordshire Forensic Services \\ Jennifer E. Storey \\ University of Kent
}

\begin{abstract}
Author note
We would like to express our special thanks to Madison Almond for her assistance on this project. Portions of this paper have been presented at the Division of Forensic Psychology Conference in the United Kingdom, 2018. Correspondence concerning this article should be addressed to Dr. Alana N. Cook, Department of Psychology, Simon Fraser University, Burnaby, V5A 1S6. Email: alanac@sfu.ca
\end{abstract}




\begin{abstract}
In Canada, there are legal provisions called Dangerous Offender and LongTerm Offender designations available to apply severe restrictions on individual liberties for persons who engage in serious offences (often repetitive) and who pose a substantial risk for violence. Since establishing the presence of a risk for violence is central to decision making in these cases, an evaluator's violence risk assessment (VRA) and expert witness testimony play a vital role in hearings for these offenders. The present study examined judicial decisions regarding expert evidence on VRAs submitted to the court in 214 Dangerous Offender/Long-Term Offender hearings identified through the Canadian Legal Information Institute database. Written judicial decisions were analysed for any comments regarding factors related to expert evidence on VRA. The commonalities that were identified, including qualities of: (1) the evaluators, (2) the VRAs completed, and (3) the evaluators' expert testimony about VRA, offer key considerations for professionals working in the mental health and criminal justice fields. They may also contribute to the development of guidelines for professionals conducting VRA used by courts.
\end{abstract}

Keywords: violence risk assessment, dangerous offender, judicial decisions, expert evidence, expert witness

\title{
Significance statements:
}

Judicial decisions in Canadian courts provide insights to judges, lawyers, and threat assessment professionals conducting violence risk assessments regarding what may be important to include in cases involving violence risk and management evidence before the court. This study offers some guidance on what courts raise regarding how evaluators can: (1) demonstrate that they have appropriate qualifications to conduct the VRA, (2) demonstrate their knowledge of and rationale 
for the sources and methods of the assessment they conduct, and (3) provide effective expert testimony in court. 


\section{Introduction}

Expert witness testimony and violence risk assessments (VRAs) play a vital role in the Canadian legal system, particularly in Dangerous Offender and Long-Term Offender hearings as these designations result in the most severe sanctions available in Canada, in terms of limiting individual liberty (Lloyd et al., 2010). A Dangerous Offender designation may be applied by the court if the court is satisfied that the offender engaged in (a) a serious personal injury offence (including aggravated assault, attempted murder, or a sexually violent offence), and constitutes a substantial risk to the life, safety, or physical or mental well-being of others or (b) a serious personal injury offence of a sexual nature and a failure to control his or her sexual impulses and a likelihood of causing injury, pain, or other evil to others through failure to control these impulses (see section 753 of the Criminal Code of Canada, 1985). A judge can impose one of three types of sentences on those deemed Dangerous Offenders: (1) an indeterminate custodial sentence with no chance of parole for 7 years; (2) a fixed sentence for the crime(s) of at least 2 years, plus a Long-Term Supervision Order for up to 10 years after the regular sentence; or (3) a regular sentence. Currently $79.3 \%$ of Danger Offenders in Canada are serving indeterminate sentences (Public Safety Canada, 2020). The purpose of the Long-Term Supervision Order option for an offender deemed a Dangerous Offender is to provide support in the community after the fixed (determinate) custodial sentence (Public Safety Canada, 2015). Offenders under Long-Term Supervision Orders are subject to standard parole sanctions as well as any special conditions deemed necessary by the judge for the individual case.

If an offender's conduct, risk, and manageability is not captured under the Dangerous Offender legislation, a designation of Long-Term Offender can be sought. In these cases, the offender does not meet criteria for a Dangerous Offender 
designation, but is still deemed to pose a substantial risk of future harm to others. One of the critical differences in these designations is that for a Long-Term Offender designation the court must be satisfied that there is a reasonable possibility that the offender's future risk can be managed in the community (Criminal Code, 1985; Glancy et al., 2001). Long-Term Offenders must be sentenced to at least a 2 year custodial sentence for their crime(s) and are subject to a Long-Term Supervision Order for up to 10 years after released from custody (Criminal Code, 1985; Public Safety Canada, 2015).

Dangerous Offender and Long-Term Offender applications are made postconviction and prior to sentencing (Public Safety Canada, 2015). The first step is for the prosecution to have the offender remanded for formal assessment, which includes an assessment of risk and manageability. This assessment is completed most often by individual psychiatrists or psychologists and otherwise by multidisciplinary teams. The assessment is completed for the court, not for the prosecution or defense, however the prosecution and defense can call on other experts to conduct additional assessments and testify at the hearing. VRAs are critical in determinations of the offenders' risk and manageability (R. v. Pike, 2010).

VRA is the process of evaluating an individual to identify the likelihood that they will commit future violence and to delineate risk management plans with the goal of preventing future violence (Guy et al., 2015; Hart, 1998). VRAs can be completed using unstructured clinical judgement or with the use of structured VRA instruments. It is widely accepted that best practice involves the use of structured VRA instruments, since unstructured clinical judgement is unreliable and no better than chance at predicting future violence (Hart, 1998; Heilbrun et al., 2017). VRA instruments can be divided into two broad categories: actuarial instruments and structured professional judgement instruments. Actuarial instruments are created 
using empirically derived algorithms to predict future violence risk in a specific offender sample (Hart, 1998). Evaluators indicate the presence of items, each numerically weighted, and items are summed to create total scores. Total scores correspond to predicted likelihoods of re-offense (Reed \& Zapf, 2017). Evaluator discretion is not permitted when using actuarial instruments. In contrast, structured professional judgement instruments guide clinical judgement of risk for offending through systematic and structured consideration of risk factors and/or protective factors for violence derived from systematic reviews of the empirical literature. Evaluators gather information about these factors and other relevant case-specific risk factors, determine their presence and relevance for the case, develop a case formulation, and using this formulation make a risk determination and identify management strategies to mitigate the identified risk (Guy et al., 2015).

Evaluators who conduct VRAs for offenders facing Dangerous Offender and Long-Term Offender hearings are typically asked to provide opinions about their findings during court hearings. This process is referred to as risk communication (Dolores \& Redding, 2009). Heilbrun and colleagues (1999) noted that effective risk communication is essential, as VRA outcomes can have serious consequences for the offender, such as an indeterminate prison sentence. This communication is provided in the evaluator's role as an expert witness for the court (for information about the criteria for the admission of expert evidence in Canada see the leading Supreme Court of Canada decision R. v. Mohan [1994], which has since been affirmed in several subsequent Supreme Court of Canada decisions).

Given Dangerous Offender and Long-Term Offender designations are the most severe in Canada, the public, and professionals in the criminal justice field, can expect the highest rigor from judges and expert evaluators who aim to assist the court in deciding whether to apply these designations. Final decisions in these hearings are 
made by the judge, as such it is important to investigate what aspects of expert evidence on VRA are included in judicial decision making.

Research on how VRA information is considered by judges and what factors within VRAs are considered by judges is limited (Blais, 2015; Cook \& Hart, 2017; Kwartner, et al., 2006; Storey et al., 2013). Studies to date have focused on judicial decision making generally (see Redding \& Murrie, 2007), the impact on judicial decisions of different forms of risk communication (Dolores \& Redding, 2009; Kwartner et al., 2006; Monahan \& Silver, 2003), judicial preferences for VRA evidence in general offending populations (Storey et al., 2013), how a specific forensic instrument, the Psychopathy Checklist-Revised (PCL-R; Hare, 2003), impacted judicial decisions in Dangerous Offender and Long-Term Offender hearings (Lloyd et al., 2010), and judge's reliance on expert evidence and partisan allegiance in opinions of risk and treatability in Dangerous Offender and Long-Term Offender hearings (Blais, 2015). Three of these studies are most relevant to the present study.

First, Storey and colleagues (2013) explored judicial comments regarding expert evidence on VRAs in Canadian courts for general offending populations. The findings indicated that there were several factors that influenced judicial decisions. Factors included the type of information used to reach an opinion and to what extent that information was relied upon in reaching the opinion. Findings also showed that the evaluator's understanding of the VRA instrument used and their ability to explain the VRA process to the court were important to judges. However, the study examined judicial discussions of VRAs in a general offending population in Canada rather than in Dangerous Offender and Long-Term Offender hearings and had a relatively small sample size $(n=35)$ due to the number of published cases available at that time.

Second, Lloyd and colleagues (2010) focused on how scores on the PCL-R are related to outcomes (indeterminate vs. determinate prison sentence) in Dangerous 
Offender hearings in Canada. The PCL-R measures psychopathic personality disorder, which is a risk factor for violence, but the PCL-R itself is not a VRA instrument. The PCL-R is often used in combination with VRA instruments and is sometimes included as a risk factor/item in VRA instruments (e.g., HCR-20; Webster, et al., 1997) since high scores on the PCL-R are associated with poor treatment outcomes and high levels of general, violent, and sexual recidivism (Hemphill et al., 1998; Looman et al., 2005). Lloyd and colleagues found that judges were significantly more likely to impose an indeterminate prison sentence for offenders who scored high on the PCL-R compared to offenders with low scores. Although this study investigated judicial decisions in Dangerous Offender hearings, it focused solely on the PCL-R and did not examine whether and how VRAs more broadly contributed to hearing outcomes.

Third, Blais (2015) examined whether judges relied on expert evidence and looked for evidence of partisan allegiance among experts in their opinions of risk and treatability in 83 Dangerous Offender and Long-Term Offender hearings in Canada. Blais found that judicial decisions were largely consistent with and predicted by experts' assessment of risk, treatability, and risk management. For instance, in $77 \%$ of cases judges relied on expert evidence to an extreme degree (defined as: accepted all information, did not disagree with any portion of the information presented) and in $22 \%$ of cases judges relied somewhat on expert evidence (defined as: accepted some of the evidence and disagreed with some aspects of the evidence), and in one case the judge did not accept the expert evidence and relied on other information to make their decision. Importantly, Blais (2015) used a quantitative design to examine agreement between experts and judges and predictors of case outcomes, but did not qualitatively investigate what judges considered when making their decisions in these cases. 
There is limited empirical information regarding how VRAs are considered by judges and thus limited guidance for professionals on how to optimally conduct VRAs and present expert evidence. This study therefore examined factors that judges include in their written decisions of expert evidence on VRA in Dangerous Offender and Long-Term Offender hearings. Specifically, this study examined judicial comments regarding the qualities of: (1) the evaluators, (2) the VRAs completed, and (3) the evaluators' expert testimony about VRA about the VRAs completed.

Dangerous Offender and Long-Term Offender hearings are the focus of the study for two reasons. First, as the most severe designations in Canada it was expected that the highest professional rigor would be displayed by the expert evaluators and judges. Second, VRA are required in every case since they speak to future risk, their importance to the decision-making process suggests that more comprehensive information would be provided.

\section{Method}

This study examined judicial decisions in Dangerous Offender and Long-Term Offender legal cases. Written judicial decisions provide an analysis of what contributed to a judge's decision. The information in a written decision is not an exhaustive list of all factors and facts presented before the court. Judicial decisions are not written in uniform fashion by all judges, nor are they considered an exhaustive list of what factors were considered by a judge and how the listed factors were weighed to make a decision. Rather, factors listed include information such as facts that the judge considered in determining the merits of the legal case, information to support the legal justification of the judge's decision, and information relevant to legal analysis of any controversies or disagreements that arose in the hearing.

\section{Procedure}


Legal cases were gathered from the Canadian Legal Information Institute, or CanLII, database where published Canadian legal cases are publicly available (www.canlii.org). CanLII attests that the Institute makes every effort to provide users with a comprehensive database, though some delays may occur in decisions being published online. The search terms used were: dangerous offender, long-term offender, violence risk assessment and risk assessment. Dangerous Offender and Long-Term Offender cases selected for inclusion occurred between January 1, 2009 and December 31, 2016. ${ }^{1}$ The search for judicial decisions was conducted on January 25, 2017. Additional inclusion criteria were that cases: (1) had a Dangerous Offender and/or Long-Term Offender application submitted, (2) had expert evidence on VRA that was discussed by the judge (VRAs are required for Dangerous Offender and Long-Term Offender hearings, so all cases of DO/LTO hearings would have at least one VRA, however judges may or may not have discussed the VRA evidence in their reasons for judgement), (3) were not appeals (to avoid duplication in the sample), and (4) the decision was published in English. ${ }^{2}$ A total of 693 legal cases were identified. After the selection process using the range of dates indicated and the five inclusion criteria (see Figure 1), 214 legal cases remained for analysis.

\section{Coding and Inter-rater Reliability}

Legal decisions were coded by one of two coders using a 24-item coding form that included items related to demographic information about the case and three apriori themes derived from previous research (Storey et al., 2013). These were judicial

\footnotetext{
${ }^{1}$ These dates were chosen because previous research had already investigated judicial decision making for general offending (which would have included Dangerous Offender and Long-Term Offender cases) and VRA in Canadian courts between 1998 and 2009 (Storey et al., 2013) and for Dangerous Offender and Long-Term Offender cases between 2006 and 2008 (Blais, 2015).

${ }^{2}$ Decisions can be published in both of Canada's official languages: English and French. The coders did not have the language skills necessary to analyze decisions written in French.
} 
comments regarding the qualities of: (1) the evaluators, (2) the VRAs completed, and (3) the evaluators' expert testimony about VRA. Ethnic or cultural origin of the offender was coded using the Canadian Census Ethnic and Cultural Origins categories (Statistics Canada, 2016).

Prior to coding, four practice cases were completed to ensure coder agreement on the criteria and any disagreements were discussed and clarified. Next, a random sample of the cases ( $n=44,20 \%$ of the sample) was coded by both raters to assess inter-rater reliability. Comparisons were made using intraclass correlation coefficients (ICC 1 ; calculated using single measures with two-way mixed effects models and absolute agreement) to determine whether raters had identified the same number of judicial comments across each of the three themes examined. The following critical values were used to interpret the ICCs: ICC > $.75=$ excellent; ICC from .60 to $.75=$ good; ICC from .40 to $.60=$ moderate; ICC $<40=$ poor (Fleiss, 1986). ICCs for the three themes ranged from good to moderate: judicial comments regarding the qualities of the evaluators was .74 (good), judicial comments regarding the VRAs was .70 (good), and judicial comments regarding evaluators' expert witness testimony was .50 (moderate).

\section{Data analysis}

Demographic variables were analysed in SPSS version 21 using frequency analysis. Judicial comments were analysed using content analysis. Content analysis is a qualitative research method that allows the researcher to obtain a deep understanding of a large amount of a descriptive information by reducing that information to trends and patterns (Krippendorff, 2004; Stemler, 2001). These trends and patterns are further examined by eliciting the relationships between the identified patterns and their frequency in the content analyzed (Vaismoradi, et al., 2013). This analysis was completed using NVivo version 11. Comments were categorized in 
NVivo based on the a-priori themes described above of judicial comments regarding qualities of: (1) the evaluators, (2) the VRAs completed, and (3) the evaluators' expert testimony about VRA. An "other" theme was also included to capture any additional comments not captured by the a-priori themes.

\section{Demographic information}

Dates and Location of Cases. The 214 cases included in the study spanned the years 2009 to 2016: in 2009, there were 23 cases (11\%), 30 cases (14\%) occurred in 2010, 21 cases (10\%) occurred in 2011, 29 cases (13\%) occurred in 2012, 24 cases (11\%) occurred in 2013, 38 (18\%) occurred in 2014, 28 cases (13\%) occurred in 2015 and 21 cases $(10 \%)$ occurred in 2016. The province of Ontario was the most frequent jurisdiction in which the cases occurred $(n=78,36 \%)$, followed by, Saskatchewan $(n$ $=47,22 \%)$, British Columbia $(n=37,17 \%)$, Alberta $(n=19,9 \%)$, Manitoba $(n=14$, $7 \%)$, Nova Scotia $(n=9,4 \%)$, the Yukon $(n=5,2 \%)$, Quebec $(n=3,1 \%)$, and the Northwest Territories $(n=2,<1 \%)$.

Sample Characteristics. Most cases were hearings for Dangerous Offender applications ( $n=149,70 \%), 22$ cases (10\%) were Long-Term Offender applications and 43 cases (20\%) were combined Dangerous Offender and Long-Term Offender applications. Where combined applications are made, offenders can be found to be Dangerous Offenders, Long-Term Offenders or neither. Just over half of the cases ( $n$ $=118,55 \%)$ involved offenders whose current conviction was for sexual violence and in $96(45 \%)$ cases offenders' current conviction was for a violent non-sexual offence.

In cases where ethnic or cultural origins were identified $(n=113,53 \%$ of all cases $)$, most offenders were identified as Indigenous people $(n=84 ; 74 \%$ of cases where ethnic or cultural origins were identified): Of which, there were offenders who identified as First Nations people $(n=50,59 \%$ of the offenders who were Indigenous), Métis people ( $n=5,6 \%$ of the offenders who were Indigenous), and 
Inuit people ( $n=1,<1 \%$ of the Indigenous people). References to Gladue Reports helped to further identify people of Indigenous ethnic and cultural origins in the 28 cases (33\% of the offenders who were Indigenous people) where no other information about the offender's ethnicity was provided. Gladue reports are court-mandated reports that provide comprehensive information about the offender's personal history. Gladue factors must be considered prior to sentencing when an offender is an Indigenous person (R. v. Gladue, 1999). As such in cases where ethic or cultural origins were not identified but a Gladue report was presented cases were identified as involving an offender who is an Indigenous person. The remaining offenders were identified as White people $(n=20,9 \%)$; Latin, Central or South American people ( $n$ $=3,1 \%)$; African people $(n=2,1 \%)$; Asian people $(n=2,1 \%)$; and Caribbean people $(n=2,1 \%)$. The ethnic or cultural origins of the offender were not identified in 101 cases ( $47 \%$ of all cases).

Nature of the Expert Evaluations. Across the 214 cases, there were 356 occasions where individual evaluators gave evidence regarding Dangerous Offender and Long-Term Offender applications, of which 212 evaluators (60\%) were psychiatrists, 105 evaluators (29\%) were psychologists, and the profession was unspecified for 39 evaluators (11\%). Some of the same experts were involved in multiple cases within the sample. A total of 110 experts provided evidence in the 214 cases. About half of the experts $(n=53,48 \%)$ provided evidence multiple times, completing an average of six assessments $(S D=6.50$, range: $2-29)$. Most experts providing evidence in multiple cases did so in two $(n=19,36 \%)$ or three cases $(n=$ $12,23 \%)$, with the remainder providing evidence in 4 to 29 cases $(n=22,42 \%)$.

Regarding the type of VRA instruments used by evaluators, a combination of actuarial instruments and structured professional judgement instruments were used most often $(n=98,46 \%)$, actuarial instruments alone were used in 58 cases $(27 \%)$, in 
21 cases $(10 \%)$ structured professional judgement instruments alone were used, and in 37 cases $(17 \%)$ the type of VRA instruments used were not specified. The frequency with which each VRA instrument was used is included in Table 1.

Nature of the Judicial Decisions. A total of 175 different judges provided judicial opinions in the 214 cases. Across the 214 cases, most of those judges ( $n=$ $144 ; 67 \%)$ only provided a judicial opinion in one case. Of the $31(17.7 \%)$ judges who provided more than one opinion, across the remaining 72 (34\%) cases examined, the average number of opinions provided was $2.32(S D=0.54$; mode $=2)$, with a range from 2 to 4 opinions ( 22 judges provided 2 opinions, 8 judges provided 3 opinions, and 1 judge provided 4 opinions). Given the low rate of multiple judgements from a single judge in the sample, we can be reasonably confident the themes identified in the analysis are generalizable, rather than a reflection of any specific judge or small group of judges.

In most cases $(n=150,70 \%)$ the judge agreed with the evaluators on the overall risk and manageability of the offender in the community. In 37 cases (17\%) the judge agreed with one evaluator but not with the other on the overall risk and manageability, in two cases (1\%) the judge agreed with neither evaluator, and in 25 cases $(12 \%)$ the judges did not comment on whether they agreed with the evaluator(s).

The average length of the judicial comments on VRA was 1,992 words (range: 28-17,706). These word counts include when judges directly quoted from other legal text and the expert(s) report. All comments fell into the three a-priori themes. A total of 653 comments were recorded across the 214 cases (Theme $1=364$ comments, Theme $2=117$ comments, Theme $3=172$ comments).

Most cases $(n=148,69 \%)$ resulted in a Dangerous Offender designation. The remaining cases resulted in a Long-Term Offender designation $(n=58 ; 27 \%)$, or no 
designation was given $(n=8,4 \%)$, only a regular sentence. In cases that led to a Dangerous Offender designation $(n=148)$, most $(n=88,59 \%)$ did not include a date when the offender would be eligible for parole. In 58 cases (39\%) eligibility was set at the maximum length of 7 years and in one case $(<1 \%)$ the length of time given before parole eligibility was 4 years.

In cases that led to a Long-Term Offender designation $(n=58), 44$ cases (76\%) included a Long-Term Supervision Order with a maximum length of 10 years. The others had a Long-Term Supervision order of 8 years $(n=2 ; 3 \%), 7$ years $(n=4$; $7 \%), 6$ years $(n=2 ; 3 \%)$, or 5 years $(n=2 ; 3 \%)$. In four cases $(7 \%)$ there were no comments regarding the length of the Long-Term Supervision Order.

\section{Results}

We present the results using the a-priori themes described in the methods that were derived from previous research (Storey et al., 2013). The three a-priori themes are judicial comments regarding: qualities of (1) the evaluators, (2) the VRAs completed, and (3) the evaluators' expert testimony about VRA. All comments fell into the three a-priori themes thus the "other" theme was not required. We present the results as the number of cases in which a subtheme was present. We identify and place emphasis the findings with the most common subthemes, defined as occurring in $25 \%$ or more of hearings (i.e., identified in at least 53 independent hearings), and provide examples of each. We identify subthemes as "uncommon" if they occurred in $24 \%$ or less of hearings and provide examples of each.

\section{Theme 1: Judicial Comments Regarding Qualities of Evaluators Who}

\section{Conducted the VRA}

There were five subthemes regarding qualities of the evaluators who conducted the VRA. Two of the subthemes occurred in more than $25 \%$ of cases. The most frequently occurring subtheme related to the evaluators' professional 
qualifications, and was present in 89 cases ( $42 \%$ of cases). Comments in this subtheme referred to whether the evaluator had a professional qualification in psychology or psychiatry, when the evaluator obtained that qualification, and at which university they obtained it. Although most comments regarding evaluators' professional qualifications were positive in nature, in one case the judge compared the professional qualifications of two evaluators and found one to be better qualified than the other, but did not expand further on this.

Judges also made frequent comments across cases regarding the work experience of the evaluators, such comments were present in 88 cases (41\% of cases). Judges commented on where the evaluator was currently employed as well as previous positions held. Further, judges mentioned how many years of work experience the evaluator had either within a position or in a total. Comments including positive expressions of how many years' experience the evaluator had in the field and comments that years' experience was irrelevant. For example, in one case the judge stated, "the credibility of the witness does not depend on the number of court appearances or years of experience" (R. v. Taylor, 2012, p. 14). Judges also highlighted whether the evaluator had any university teaching experience, any experience working abroad, and any assessment or treatment experience with offenders who are Indigenous people.

There were three subthemes that occurred in less than $25 \%$ of cases. One uncommon subtheme was the evaluators' previous experience conducting Dangerous Offender and Long-Term Offender assessments ( $n=36,17 \%$ of cases). These comments referred to how many times the evaluator had prepared reports for Dangerous Offender and Long-Term Offender hearings and how many times the evaluator had testified at Dangerous Offender and Long-Term Offender hearings. Of note, in two cases the judge highlighted the evaluators' lack of experience with 
Dangerous Offender or Long-Term Offender hearings. In one of these cases, the judge indicated that the evaluator's work experience had so far been mostly in civil cases. As the evaluator had no previous experience with Dangerous Offender or Long-Term Offender hearings, the judge commented that the evaluator might have underestimated such hearings and what they require of the evaluator as an expert witness. In the second case, the judge stated that although the two evaluators providing assessments in the case did not have the same level of experience with Dangerous Offender and Long-Term Offender assessments, the judge did not see them as being in competition.

Another uncommon subtheme was the evaluators' previous experience as an expert witness ( $n=11,5 \%$ of cases). Examples of comments in this subtheme include comments about the evaluators general experience as an expert witness in Canadian courts, that the specific jurisdiction hearing the case had previously accepted the evaluator as an expert witness in a prior case or cases (e.g., "His evidence has been recognized by all levels of the Saskatchewan courts, as well as courts of other provinces" [R. v. Slippery, 2016, para. 156]), and how many years of providing expert evidence to court the evaluator had.

The final uncommon subtheme was the evaluator's reputation in their field ( $n$ $=4,2 \%$ of cases). Comments in this subtheme were positive, such as the expert having "a wealth of experience" and "extraordinary experience" in their field.

\section{Theme 2: Judicial Comments Regarding Qualities of the VRAs Completed}

There were eight subthemes present regarding the qualities of the VRAs completed. All the subthemes in this theme were uncommon, occurring in less than $25 \%$ of the cases. First of the uncommon subthemes was the style or overall quality of the VRA ( $n=14$ cases, $7 \%$ of cases). Examples of comments included positive comments about the expert report, judges used phrases like "extensive report", 
"comprehensive", "very thoughtful", and "very detailed and useful", and negative comments about the report such as, the VRA report included typographical errors and the report contained "points that were obvious".

Second, was the sources of information or materials used in the VRA, occurring in 14 cases ( $7 \%$ of cases). This theme has comments related to whether the evaluator interviewed the offender as part of the assessment, or the number of times that an offender was interviewed, and the length of the interview of the offender. Judge's also commented at times that there were problems with the materials reviewed. Only some judges specified what these problems were, for example problems included that evaluators were relying on unproven charges, that the evaluator failed to consider previous convictions when assessing the future risk of reoffending. Others made general statements about the sources of information (e.g., no problems with source of information), or comments that two evaluators had access to slightly different information).

Third, was judicial preference for certain VRA tools occurring in 14 cases (7\% of cases). Preferences were expressed for specific tools, for example one judge preferred the Static-99R over the SORAG. In one case, the judge expressed a preference for actuarial instruments over unstructured professional judgement and in two cases the judge preferred that evaluators use a combination of actuarial and structured professional judgement instruments.

Fourth, was criticism of the VRA tool used ( $n=13$ cases, $6 \%$ of cases). Comments in this subtheme included criticism about the development of the VRA tool used (e.g., that validation of the VRA tool used was conducted on a small sample, did not include a longitudinal design), the accuracy of the VRA tool used (e.g., commentary on the negative impact error associated with violence risk predictions made), and criticism about the use of an out of date versions of the VRA tool used (in 
all of these cases the evaluators had used the Static-99 instead of the updated Static99R). Further, one judge debated the age cut-off of an actuarial tool. The age cut-off refers to the age group of offenders that the VRA instrument had been designed to assess; different VRA instruments have different age cut-off points. In this case, the judge made comments about how the instrument could be suitable for an offender who was 18 years old, but not for an offender who will turn 18 in a few days.

Fifth, was the outcome of the VRA tools ( $n=12$ cases, $6 \%$ of cases). Within this subtheme, judges pointed out issues with the outcomes reported by evaluators. For example, one judge noted that the overall risk level refers to how the offender's risk level on the instruments compares to the validation sample of the instrument and not an individual offender (reflecting a common criticism of actuarial instruments: the application of sample-specific, group norms to an individual case; see Reed \& Zapf, 2017). Judges also commented on the format in which the VRA outcome was presented. For instance, they noted when there was no definite conclusion provided, when they preferred risk to be reported as a category, such as moderate or high risk instead of a percentage and conversely when they preferred risk to be reported as a percentage rather than a category.

Sixth, was a comparison between two VRAs ( $n=10$ cases, $5 \%$ of cases). Comments in this subtheme related to evaluators who had obtained different overall risk scores using the same VRA instrument. In some cases, the judge further discussed whether the difference between scores was within an acceptable margin and what possible reasons could account for the differences in scores. Possible reasons for differences raised by judges included that the evaluators had relied on slightly different information when completing their assessments and that only one of the evaluators had the opportunity to interview the offender. Conversely, judges also highlighted when two or more evaluators representing different parties arrived 
independently at the same or similar conclusions. In one case, the judge pointed out that the evaluator used only two VRA instruments whereas other evaluators in the same case used more than two VRA instruments. Similarly, in another case the judge highlighted that one evaluator had not included protective factors in their VRA whereas another evaluator in the same case had included protective factors.

Seventh, was the content of the VRA tools ( $n=8,4 \%$ of cases). Comments made here were not criticisms but statements about the content of the VRA tools. For example, one judge commented that the HCR-20 does not address sexual recidivism and that actuarial instruments do not provide any information about the type or severity of possible future offences.

The last uncommon subtheme was applicability of VRA with defendants who are Indigenous people ( $n=3,1 \%$ of cases). One judge commented that they accepted VRA instruments as reliable instruments to assess violence risk among offenders who are Indigenous people. Comments were also made that actuarial instruments were not suitable to assess violence risk among people who are Indigenous and that there is the lack of research on the suitability of using existing VRA instruments (generally) to assess Indigenous people. In one case, the judge praised the evaluator for considering factors related to Indigenous heritage when conducting their VRA. In another case, the judge made statements that factors that are legally required to be considered in sentencing of offenders who are Indigenous people in Canada (i.e., in Canada, referred to as Gladue factors; $R$. v. Gladue, 1999) need to be considered.

\section{Theme 3: Judicial Comments Regarding Qualities of the Evaluators' Expert Witness Testimony about the VRA}

There were four subthemes present regarding qualities of the evaluators' expert witness testimony. Only one subtheme was present in over $25 \%$ of cases: the overall impression of the evaluators ' testimony, which was present in 61 cases (29\% 
of cases). Many of the overall impressions provided by judges were positive and included words like: "thoughtful testimony", “credible and knowledgeable witness", "useful”, "well-reasoned and objective testimony", "was significant assistance to court", "balanced and accurate", and "measured, thoughtful, and careful witness". In some cases, comments were negative. For example, judges highlighted testimony that they found to be "obvious", "unhelpful" or "speculative".

The first of the three uncommon subthemes was judicial agreement with the evaluators' testimony ( $n=42$ case, $20 \%$ of cases). These consisted of general statements from the judge that they agreed with the testimony about the overall violence risk, recommended treatment plan, and/or manageability of the offender in the community.

Second, was judicial criticism of the testimony ( $n=41$ cases, $19 \%$ of cases). In this subtheme, judges commented on: an evaluators' lack of knowledge about available treatment/community resources, an evaluators potential bias, and inconsistencies between evaluators' reports and their testimony. Judges were also critical when evaluators were not able to answer questions regarding their VRA. Some judges made critical comments when evaluators did not offer an opinion regarding Dangerous Offender or Long-Term Offender status and, in contrast, other judges made critical comments when evaluators commented on legal matters.

The final uncommon subtheme was judicial disagreements with testimony $(n=$ 22 case, $10 \%$ of cases). These consisted of general statements from the judge indicating that they disagreed with the testimony with respect to specific evaluator's opinions (e.g., a judge rejected the evaluators' professional opinions, including opinions that sexual preference is changeable, that it is possible to cure pedophilia and that sex drive decreases with age), and that they disagreed with the overall violence 
risk level identified, the recommended treatment plan, and/or the evaluator's conclusion about the manageability of the offender in the community.

\section{Discussion}

The present study examined judicial decisions regarding evaluator expert witness evidence regarding VRAs completed in Dangerous Offender and Long-Term Offender hearings. Based on previous research conducted by Storey and colleagues (2013), three themes related to qualities of: (1) the evaluators, (2) the VRAs completed, and (3) the evaluators' expert testimony about VRA, referenced in the judicial decision were examined. Although a substantial number of comments were made by judges in each of the three a-priori themes and no comments were identified outside of these themes, there was a mix of subthemes that were common and uncommon across cases. The diversity in commentary provided by judges in this sample is not surprising as the nature of the cases varied, the complexity of the evaluations varied, and there were many different evaluators and judges. With this, as judges most often agreed with experts in our study and in previous research (Blais, 2015) we would not expect themes where judges comment on information relevant to any controversies or disagreements that arose in the hearing to occur frequently. As a result, we consider both the common findings and the uncommon findings from the data to be important to evaluators, lawyers, and judges. The discussion will therefore emphasize our major findings (i.e., common subthemes what occurred in $25 \%$ or more of hearings), and also discuss those findings that were less common. Given the lack of published guidelines, we hope that the findings may be used in conjunction with other research and standards of practice by professionals working in this field. We think the common and uncommon findings will be particularly useful those who are new to this field as they may be less familiar with how aspects of their own experience and training, VRA reports, and potential expert testimony may be 
optimally presented to the court. To facilitate the use of the findings we have created Table 2 which outlines considerations for completing VRAs intended for court.

\section{Theme 1: Judicial Comments Regarding Qualities of Evaluators Who}

\section{Conducted the VRA}

The first theme reflected judicial comments on the qualities of the evaluators. It was clear that evaluators' professional qualifications and work experience were noted by judicial decision makers. Judicial comments on professional qualifications focused on an evaluators' professional qualifications in psychology or psychiatry and when and where these qualifications were obtained. Most commentary on professional qualifications was positive in nature. Comments about work experience were focused on current and previous employment and years of experience (though judges referenced this, it was not always considered important). Comments on professional qualifications and work experience are expected as consideration of these factors is required by the fourth criteria for the admissibility of expert evidence in Canada set out by R. v. Mohan (1994): a properly qualified expert. Less common subthemes included an evaluators' experience conducting Dangerous Offender and Long-Term Offender assessments, previous experience as an expert witness, and an evaluators' reputation in their field.

\section{Theme 2: Judicial Comments Regarding Qualities of the VRAs Completed}

The second theme related to qualities of the VRAs completed. There were no common subthemes found in this theme (i.e., present in $25 \%$ or more of cases). The findings did indicate that the overall quality of the VRA assessment is referenced by judges. The findings indicated that judges positively commented on reports that were extensive, comprehensive, thoughtful, and detailed. Judges negatively commented on reports with typographical errors and reports that included statements that the judge found to be obvious. We expected the overall quality of VRAs to include positive 
given that psychiatrists and psychologists are expected to comply with basic professional standards when conducting assessments (see for example, College of Psychologist of British Columbia, 2014).

The findings also highlighted the importance of the sources of information on which the VRA is based. This included comments regarding the presence of interviews with the evaluee and the type and quality of the materials reviewed. Sources of information are critical; an assessment is only as good as the information on which it is based. As noted by the judges, a VRA is limited by, and can change quite dramatically, based on the sources of information available to the evaluator. For example, if an evaluator relied on incomplete, unreliable, invalid, or even simply different information to another evaluator, the opinions formed in their assessment are likely to be limited and potentially inaccurate. It is challenging to gather complete, reliable, and valid information for VRAs and it is an unrealistic expectation for evaluators to have identical information in the same case. For example, even if all collateral documentation is identical, if both evaluators interview the offender, the information gathered in their respective interviews is likely to be somewhat different. The finding that there was some concern about the sources of information used in assessment was expected because there are no professional standards regarding the quality of the information sources required to form opinions in assessments (see for example, College of Physicians and Surgeons of British Columbia, 2019). This becomes even more relevant when we expand to VRAs outside of a Dangerous Offender/Long-Term Offender hearing purpose where many other types of professionals (e.g., police, security professionals) may be conducting VRAs with varying sources of information on which to base their opinions.

In some cases, judges expressed preference for certain risk assessment tools, criticized certain tools, or indicated a preference for how they would like risk ratings 
reported (i.e., categories vs. percentages). Although the details of these findings may be useful to explore, the broader implication is that judges have a range of preferences regarding the VRA instruments used and the delivery of results. These preferences may or may not align with an evaluator's professional practice. For example, a judge who prefers the combination of actuarial and structured professional judgment instruments may contrast with an evaluators preference to use one method or the other, as was the case in about one third of our sample (37\% of assessments included only actuarial tools or only structure professional judgement tools). These findings provide some implications for standards of practice related to what evaluators should consider when undertaking a VRA. We provide details of these implications for practice in Table 2.

The lack of common findings related to the subtheme of the applicability of VRA with defendants who are Indigenous people was notable. The data from this study (2009-2016) directly proceeded a critical national discussion in Canada both legally (Ewert v. Canada, 2018) and scientifically (Haag, 2016) regarding the application of VRA instruments with people who are Indigenous. Given the timing of the cases examined we would not necessarily expect a robust discussion of the application of VRA instruments with offenders who are Indigenous people. However, a large portion of our sample was Indigenous people $(n=84 ; 39 \%)$. As Gladue factors must be considered prior to sentencing for an offender who is an Indigenous person (R. v. Gladue, 1999) and the fact there is an alarming overrepresentation of Indigenous peoples in the Canadian Criminal Justice System ${ }^{3}$ we would have

\footnotetext{
${ }^{3}$ Indigenous people represent $4.9 \%$ of the Canadian Population and account for $23.1 \%$ of the federal offender population (Public Safety Canada, 2018) and within the Dangerous Offender population (Indigenous offenders represent $34.5 \%$ of the Dangerous Offender population; Public Safety Canada, 2018).
} 
expected more discussion on Indigenous culture as it would have been relevant to sentencing.

\section{Theme 3: Judicial Comments Regarding Qualities of the Evaluators' Expert}

\section{Witness Testimony about the VRA}

The third theme was the qualities of the evaluators' expert testimony about the VRA. Given the low rater agreement in this theme, we interpret these results with caution. The results indicated that judges provided an overall impression of the evaluators' testimony, with many of these comments being positive. Positive comments included that the testimony was thoughtful, useful, well-reasoned, objective, and balanced. Judges commented negatively on such things as a testimony that they found to be obvious, unhelpful, or speculative. Judges also provided specific criticism of testimony (e.g., evaluators demonstrating a lack of knowledge about the case, evaluators demonstrating a lack objectivity when testifying, evaluators providing verbal and written evidence, and evaluators unable to answer questions about their VRA). The comments in this subtheme are in keeping with what we would expect from the court, particularly around objectivity, per the Code of Conduct for Expert Witnesses in the Federal Court Rules (Rule 52.2, 2019) ${ }^{4}$ and are important given the findings of adversarial allegiance by expert evaluators in adversarial legal proceedings (Murrie, et al., 2013). These comments are also in keeping with what would be expected of evaluators conducting VRAs based on the empirical literature, including that evaluators ought to be knowledgeable and objective in their work (Saunders, 2000), and what would be expected based on common sense, such as

\footnotetext{
${ }^{4}$ The Federal Court Rules, Schedule (Rule 52.2) Code of Conduct for Expert Witnesses, General Duty to the Court states that "(1) an expert witness...has an overriding duty to assist the Court impartially on matters relevant to his or her area of expertise. (2) this duty overrides any duty to a party to the proceeding, including the person retaining the expert witness. An expert is to be independent and objective. An expert is not an advocate for a party." (line $1 \& 2$ ).
} 
providing consistent opinions in a report and oral testimony. Other subthemes referenced judges' agreement and disagreement with raters. Judges stated agreement with evaluators in about twice as many cases as they disagreed. This is consistent with previous research by Blais (2015) that demonstrated judges' reliance on expert evidence was most often extreme (as defined by: accepted all information, did not disagree with any portion of the information presented).

The findings across all themes from this study are generally consistent with the only previous research that investigated judicial discussion of expert evidence on violence risk in Canada (Storey et al., 2013). Nevertheless, a few differences were identified, for instance, Storey and colleagues found that judges provided more varied comments and several concerns related to evaluators' qualifications and work experience. This difference may be due to the nature of professionals completing VRAs in each study. Storey and colleagues reviewed general criminal cases where VRAs were conducted by a range of professionals (e.g., probation officers, police officers, psychologists, psychiatrists) with varied experience whereas the present study reviewed only Dangerous Offender and Long-Term Offender hearings which were primarily conducted by psychologists or psychiatrists. Storey et al. also found that judges' comments on the ability of evaluators to explain the VRA process to the court was important but we did not find this as a common theme. Again, this may be related to our sample, as these evaluators are all high-qualified and likely provided clear explanations of the VRA process, thus not resulting in comments by judges.

Taken together, we examined what judges found important to note about VRA in their decision making, not a comprehensive examination of all factors that judges considered relevant in their decision making. Our findings indicated there are clearly a breadth of factors that judge's address in written decisions regarding VRA. There are of course other factors related to VRA that judges will have considered in their 
decision making, including and importantly case law and legal precedent, legal principles (e.g., deterrence, denunciation), and other factors outside those addressed in the VRA.

\section{Limitations}

This study has some limitations that should be considered in the interpretation of the results. First, generalizability of the results is limited to high-stakes Canadian cases. In our opinion, this is a good litmus test of judges' views on VRA evidence because we expect the highest level of rigor in such cases. Nevertheless, the context of the cases reviewed does limit the generalizability of the findings to different types of cases because other factors, including the types of professionals conducting risk assessments (e.g., police, probation, parole, security professionals), the time and scope of assessment, and the sources of information on which the assessment is based will likely differ in cases that do not involve Dangerous Offender or Long Term Offender hearings. For instance, the types of cases in our study are characterized by evaluators who are primarily psychiatrists and psychologists conducting the VRAs, and typically the evaluators have more time to complete the assessment and more file information in these types of assessment then assessments at the time of arrest, or pretrial.

Another limitation related to the generalizability of our study, is that the published decisions examined represent only a portion of all the Dangerous Offender and Long-Term Offender hearings held during the period examined. Though CanLII indicates they do intend their database to be comprehensive and up-to-date, there are no data to confirm the number of unpublished hearings. We do know that during the period examined there were 374 offenders given a Dangerous Offender designation (Public Safety Canada, 2018). Our data do not include appeal cases or follow a specific case to see if a designation was changed on appeal, but the number of 
Dangerous Offender designations from Public Safety Canada indicates that our data represent only a portion of cases heard in the period reviewed.

Third, there are several limitations to our ability to interpret the data. We chose to use published legal decisions as this approach can offer unique insights regarding how VRAs are reviewed by judges. Nevertheless, this means that we are limited to what the judges decided to include in their written decisions. Although this method allowed us to obtain data on a larger number or cases and from a larger number of judges then would likely be possible with a different research design (e.g., using semi-structured interviews), the results do not represent an exhaustive list of what factors were considered and how they contributed on judges' decisions. With this method, we are also reliant on the judge's interpretation of the VRA evidence and cannot compare it to the reports and testimony of evaluators.

Fourth, the nature of the data did not allow us to determine the level of experience of the evaluators or judges and thus we could not identify whether this impacted the quality or interpretation of the VRAs. VRAs may vary based on evaluators experience (such as years of experience or psychiatrist/psychologist, or total number of VRA completed) or judges' experience (such as years of experience as a judge or number of Dangerous Offender hearings completed).

\section{Implications for Research}

Future studies can address the limitations of the current study. One future study could be to examine judges' decisions by directly asking judges through interviews or questionnaires what are all the factors they consider in making decisions about VRA and how these different factors are weighted. Another area for future research is to examine judicial decisions in cases of Indigenous people. In this study, we did not explore if and how judges discussed Indigenous culture beyond the demographic variable and our initial coding criteria. Given the important issues 
identified through the Ewert case, future research should explore how Indigenous culture is considered in VRA expert evidence and if Indigenous culture is discussed more frequently and the nature of those discussions following Ewert v. Canada, 2018.

We also suggest that research work should examine the broad relevance of VRAs in judicial decision making across different jurisdictions as we have done in this study to allow for cross-national comparisons. Cross-national comparisons can include comparable research designs and question to the current study, or build on the present research by examining other factors, such as culture or ethnicity, or evaluator background, training, and experience. This information will help to expand our understanding of what judges are considering in different jurisdictions and if there is any consensus cross-nationally on these matters. This could assist professionals in the field to determine if and how they should be considering factors considered in Canada and other jurisdictions in their own practice.

\section{Implications for Practice}

The findings have several practical implications. We believe that due to the serious nature of the cases reviewed and as a result the rigor of the VRAs and the judicial analysis, the implications of our findings are relevant to all evaluators providing VRA evidence in court. To streamline our findings into practice we have developed considerations for completing VRAs intended for courts based on judicial comments and have presented these in Table 2. Evaluators can consider what judges have referenced and, if not in conflict with an evaluator's field of practice and feasible to include, incorporate these considerations in their VRA or include information about these considerations in their curriculum vita. The considerations can also serve as areas that evaluators should be aware of and prepared to be questioned about when giving evidence; similarly, lawyers can use these areas to guide lines of questioning of experts in court. As Storey et al. (2013) called for, we echo a need for professional 
associations to generate guidelines for providing expert evidence in court. No such guidelines exist. In addition to the considerations presented in Table 2 and by Storey et al., future guidelines for evaluators ought to include a review of other empirical findings, texts providing guidance on expert evidence to the court (e.g., Brodsky \& Gutheil, 2015), case law or other legal guidance (for Canada, Public Safety Canada, 2009), and general professional guidelines for forensic psychology (e.g., American Psychological Association, 2013).

\section{Conclusion}

Dangerous Offender and Long-Term Offender designations are the most severe penalties possible in the Canadian criminal justice system, as these designations can lead to profound restrictions on an individual's liberty. As such, the VRAs and evaluators' expert witness testimony that is required in these proceedings can have significant impacts on individual offender rights and public safety. Due to their importance, the present study examined judicial decisions regarding expert evidence on VRAs in Dangerous Offender and Long-Term Offender hearings. The findings from this study offer some considerations for professionals working in the mental health and criminal justice fields and may be considered in the development of guidelines for expert evidence regarding VRAs in Canada, and potentially more broadly where expert evidence on VRA is used by the courts. 


\section{References}

American Psychological Association. (2013). Specialty guidelines for forensic psychology. American Psychologist, 68(1), 7-19. https://www.apa.org/pubs/journals/features/forensic-psychology.pdf

Blais, J. (2015). Preventative detention decisions: Reliance on expert assessments and evidence of partisan allegiance within the Canadian context. Behavioral Sciences and the Law, 33, 74-91. https://doi.org/10.1002/bs1.2155

Brodsky, S. L. \& Gutheil, T. G. (2016). The Expert Expert Witness: More maxims and guidelines for testifying in court (Second Ed.). American Psychological Association.

College of Physicians and Surgeons of British Columbia (2019). Professional Guideline: Independent Medical Examinations. http://www.cpsbc.ca/

College of Psychologists of British Columbia (2014). CPBC Code of Conduct. http://www.collegeofpsychologists.bc.ca/

Cook, A. N. \& Hart, S. D. (2017). Violence Risk Assessment Across Nations and Across Cultures: Legal, Clinical, and Scientific Considerations. In R. Roesch and A. N. Cook, Handbook of Forensic Mental Health Services (131-152). Routledge.

Criminal Code of Canada, [1985] R.S.C., c.46, s.231(6)

Dolores, J. C., \& Redding, R. E. (2009). The effects of different forms of risk communication on judicial decision making. International Journal of Forensic Mental Health, 8(2), 142-146.

https://psycnet.apa.org/doi/10.1080/14999010903199407

Ewert v. Canada, [2018] SCC 30

Federal Court Rules, [2019] SOR/98-106. http://www.law-lois.justicegc.ca/ 
Fleiss, J. L. (1986). The design and analysis of clinical experiments. John Wiley \& Sons.

Glancy, G. D., Regehr, C., \& Bradford, J. (2001). Sexual predator laws in Canada. American Academy of Psychiatry and the Law, 29, 232-237.

Guy, L. S., Douglas, K. S., \& Hart, S. D. (2015). Risk assessment and communication. In B. L. Cutler \& P. A. Zapf, (Eds.), APA handbook of forensic psychology (Vol 1, pp. 35-86). American Psychological Association.

Haag, A. (Ed.) (2016). Ewert v. Canada: International implications for cultural consideration for threat assessment [Special issue]. Journal of Threat Assessment and Management, 3(2).

Hare, R. D. (2003). Hare PCL-R. Rating Booklet. (2nd ed.). Multi-Health System.

Hart, S. D. (1998). The role of psychopathy in assessing risk for violence: Conceptual and methodological issues. Legal and criminological psychology, 3(1), 121-137.

Heilbrun, K., Dvoskin, J., Hart, S., \& McNiel, D. (1999). Violence risk communication: Implications for research, policy, and practice. Health, Risk \& Society, 1(1), 91-105.

Heilbrun, K., Fairfax-Columbo, J., Wagage, S., \& Brogan, L. (2017). Risk assessment for future offending: The value and limits of expert evidence at sentencing. Court Review, 53, 116-125.

Hemphill, J. F., Hare, R. D., \& Wong, S. (1998). Psychopathy and recidivism: A review. Legal and criminological Psychology, 3(1), 139-170.

Krippendorff, K. (2004). Content analysis: An introduction to its methodology. Second edition. Sage Publication.

Kwartner, P. P., Lyons, P. M., \& Boccaccini, M. T. (2006). Judges' risk communication preferences in risk for future violence cases. International 
Journal of Forensic Mental Health, 5(2), 185-194.

$\underline{10.1080 / 14999013.2006 .10471242}$

Lloyd, C. D., Clark, H. J., \& Forth, A. E. (2010). Psychopathy, expert testimony, and indeterminate sentences: Exploring the relationship between Psychopathy Checklist-Revised testimony and trial outcome in Canada. Legal and Criminological Psychology, 15(2), 323-339. https://doi.org/10.1348/135532509X468432

Looman, J., Abracen, J., Serin, R., \& Marquis, P. (2005). Psychopathy, treatment change, and recidivism in high-risk, high-need sexual offenders. Journal of Interpersonal Violence, 20(5), 549-568. doi: 10.1177/0886260504271583

Monahan, J. \& Silver, E. (2003). Judicial decision thresholds for violence risk management. International Journal of Forensic Mental Health, 2(1), 1-6. https://doi.org/10.1177/0886260504271583

Murrie, D. C., Boccaccini, M. T., Guarnera, L., \& Rufino, K. A. (2013). Are forensic experts biased by the side that retained them? Psychological Science, 24(10). https://doi.org/10.1177\%2F0956797613481812

Public Safety Canada (2009). The investigation, prosecution and correctional management of high-risk offenders: A national guide. https://www.publicsafetycanada.gc.ca/Public Safety Canada (2015). Dangerous Offender Designation. https://www.publicsafety.gc.ca/

Public Safety Canada (2018). 2017 Corrections and Conditional Release Statistical Overview. https://www.publicsafety.gc.ca/ Public Safety Canada (2020). 2019 Corrections and Conditional Release Statistical Overview. Retrieved from https://www.publicsafety.gc.ca R. v, Gladue, [1999] 1 SCR 688. https://canlii.org/ R. v. Mohan, [1994] 2 SCR 9. https://canlii.org/ 
R. v. Pike, [2010] BCCA 401. https://canlii.org/

R. v. Slippery, [2016] SKPC 131. https://canlii.org/

R. v. Taylor, [2012] ONSC 1025. https://canlii.org/

Reed, A. L., \& Zapf, P. A. (2017). Criminal Forensic Assessment. In R. Roesch and A. N. Cook, Handbook of Forensic Mental Health Services (pp. 79-103). Rutledge.

Redding, R. E. \& Murrie, D. C. (2007). Judicial decision making about forensic mental health evidence. In A. M. Goldstein (Ed.), Forensic psychology: Emerging topics and expanding roles (pp. 683-707). Wiley.

Saunders, J. W. S. (2000). Experts in court: A view from the bench. Canadian Psychology/Psychologie Canadienne, 42(2), 109-118. https://doiorg.proxy.lib.sfu.ca/10.1037/h0086885

Statistics Canada (2016). Census Program. http://www12.statcan.gc.ca/censusrecensement/index-eng.cfm

Storey, J. E., Campbell, V. J., \& Hart, S. D. (2013). Expert evidence about violence risk assessment: A study of Canadian legal decisions. International Journal of Forensic Mental Health, 12(4), 287-296.

https://doi.org/10.1177\%2F0956797613481812

Stemler, S. (2001). An overview of content analysis. Practical assessment, research \& evaluation, 7(17), 137-146.

Vaismoradi, M., Turunen, H., \& Bondas, T. (2013). Content analysis and thematic analysis: Implications for conducting a qualitative descriptive study. Nursing \& health sciences, 15(3), 398-405. https://doi.org/10.1111/nhs.12048

Webster, C. D., Douglas, K. S., Eaves, D., \& Hart, S. D. (1997). HCR-20: Assessing risk for violence, Version 2. Mental Health, Law, \& Policy Institute, Simon Fraser University. 
Figure 1. Selection Process of Legal Cases Using CanLII Database

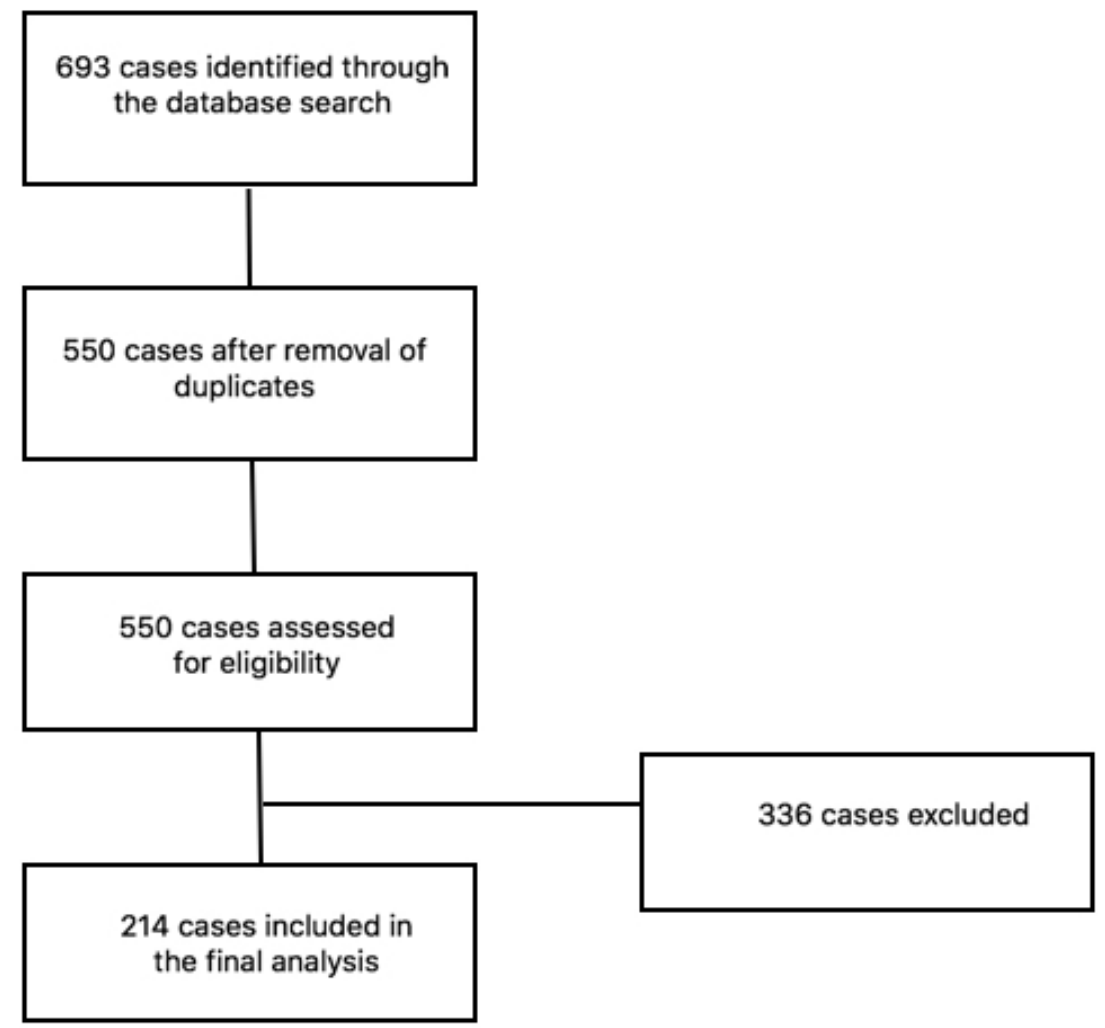


Table 1

Frequency and Percent of Instruments Used by Evaluators

\begin{tabular}{lc}
\hline Instrument & $n(\%)$ \\
\hline Psychopathy Checklist - Revised (PCL-R) & $121(57 \%)$ \\
Violence Risk Appraisal Guide (VRAG) & $94(24 \%)$ \\
Historical Clinical Risk Management - 20 (HCR-20) & $72(19 \%)$ \\
Sexual Offender Risk Appraisal Guide (SORAG) & $64(17 \%)$ \\
STATIC 99 & $47(12 \%)$ \\
STATIC 99-R & $42(11 \%)$ \\
Sexual Violence Risk (SVR-20) & $26(7 \%)$ \\
Spousal Assault Risk Assessment Guide (SARA) & $10(3 \%)$ \\
Risk for Sexual Violence Protocol (RVSP) & $9(2 \%)$ \\
Violence Risk Scale (VRS) & $8(2 \%)$ \\
Level of Service/Case Management Inventory (LS/CMI) & $6(1 \%)$ \\
Level of Service Inventory - Revised (LSI-R) & $5(1 \%)$ \\
STABLE 2007 & $1(<1 \%)$
\end{tabular}




\section{Table 2}

Considerations for completing VRAs intended for Courts based on Judicial comments

\section{Qualities of the Evaluators}

- Professional Qualifications: Evaluators engaging in VRA should have the appropriate professional qualifications and training to conduct VRA and report (or be able to report) where and when they received these qualifications and training.

- Work experience: Evaluators engaging in VRA should have relevant work experience (previous or current) and report (or be able to report) the nature of that experience and length of time in each position.

- Previous experience with type of VRA and experience as an expert: Evaluators engaging in VRA should have experience with the type of VRA being conducted and ideally in the context in which they are providing the expert evidence. Evaluators should report (or be able to report) how many VRAs they have completed and/or provided testimony for.

Qualities of the Violence Risk Assessments (VRA)

- Overall Qualities of the VRA: Evaluators can aim to provide assessments that are extensive (if appropriate for the context), comprehensive, thoughtful, and detailed and ensure points included are relevant and written reports are proofread.

- Sources of Information: Evaluators should clearly state what materials they relied on in completing their VRA and consider the quality and nature of the materials relied on in completing the VRA. This includes details on whether they relied on an interview with the evaluee and 
their rationale/reasons if they did not as well as the implications that this has on the opinions given.

- VRA Tools: Evaluators should provide (or be able to report on) the rationale for their overall risk scores on instruments used to conduct their VRA and the rationale for how they are presenting the outcome of their risk assessment (i.e., categories, percentages). Regarding any instruments used, evaluators should ensure that they are aware of the intended population and context in which the tool is to be used, of any required administration procedures, of any limitations of the tool (generally and in the specific case under assessment) and of any relevant research about the tool including general research support and research supporting the application of VRA instruments given the specific nature of the case.

\section{Qualities of Evaluator Expert Witness Testimony}

- Overall Qualities of the Testimony: Evaluators should provide testimony that reflects their expert knowledge, is wellreasoned/supported by the facts, and is objective and balanced. Evaluators should avoid testimony that is obvious or speculative (though "obvious" may be challenging to conceptualize).

- Specific criticisms of testimony: Evaluators should be knowledgeable about the case, including about treatment and community resources that are available for evaluees, maintain objectivity when testifying, provide consistent verbal and written evidence, and be able to answer questions about their VRA. 
Note. We have included considerations from all but three subthemes present in our findings. We did not include considerations related to reputation, general statements of agreement with the experts' opinion, or general statements of disagreement with the experts' overall opinion as these three themes are out the evaluators control when completing the VRA. Considerations from common subthemes, defined as occurring in $25 \%$ of more of hearings, are bolded. 